\title{
Atmospheric turbulence affects wind turbine nacelle transfer functions
}

\author{
Clara M. St. Martin ${ }^{1}$, Julie K. Lundquist ${ }^{1,2}$, Andrew Clifton ${ }^{2}$, Gregory S. Poulos ${ }^{3}$, and Scott J. Schreck \\ ${ }^{1}$ Department of Atmospheric and Oceanic Sciences (ATOC), University of Colorado at Boulder, 311 UCB, \\ Boulder, CO 80309, USA \\ ${ }^{2}$ National Renewable Energy Laboratory, 15013 Denver West Parkway, Golden, CO 80401, USA \\ ${ }^{3}$ V-Bar, LLC, 1301 Arapahoe Street, Suite 105, Golden, CO 80401, USA
}

Correspondence to: Clara M. St. Martin (clara.st.martin@ colorado.edu)

Received: 8 December 2016 - Discussion started: 14 December 2016

Revised: 16 April 2017 - Accepted: 24 April 2017 - Published: 2 June 2017

\begin{abstract}
Despite their potential as a valuable source of individual turbine power performance and turbine array energy production optimization information, nacelle-mounted anemometers have often been neglected because complex flows around the blades and nacelle interfere with their measurements. This work quantitatively explores the accuracy of and potential corrections to nacelle anemometer measurements to determine the degree to which they may be useful when corrected for these complex flows, particularly for calculating annual energy production (AEP) in the absence of other meteorological data. Using upwind meteorological tower measurements along with nacelle-based measurements from a General Electric (GE) 1.5sle model, we calculate empirical nacelle transfer functions (NTFs) and explore how they are impacted by different atmospheric and turbulence parameters. This work provides guidelines for the use of NTFs for deriving useful wind measurements from nacelle-mounted anemometers. Corrections to the nacelle anemometer wind speed measurements can be made with NTFs and used to calculate an AEP that comes within $1 \%$ of an AEP calculated with upwind measurements. We also calculate unique NTFs for different atmospheric conditions defined by temperature stratification as well as turbulence intensity, turbulence kinetic energy, and wind shear. During periods of low stability as defined by the Bulk Richardson number $\left(R_{\mathrm{B}}\right)$, the nacelle-mounted anemometer underestimates the upwind wind speed more than during periods of high stability at some wind speed bins below rated speed, leading to a steeper NTF during periods of low stability. Similarly, during periods of high turbulence, the nacelle-mounted anemometer underestimates the upwind wind speed more than during periods of low turbulence at most wind bins between cut-in and rated wind speed. Based on these results, we suggest different NTFs be calculated for different regimes of atmospheric stability and turbulence for power performance validation purposes.
\end{abstract}

Copyright statement. The US Government retains - and the publisher, by accepting the article for publication, acknowledges that the US Government retains - a nonexclusive, paid-up, irrevocable, worldwide license to publish or reproduce the published form of this work, or to allow others to do so, for US Government purposes.

\section{Introduction}

Traditionally, each wind turbine has an anemometer and wind vane mounted on its nacelle, behind the hub (Fig. 1). Measurements collected from these instruments are used for yaw control and turbine cut-in and cut-out procedures. Nacelle measurements could also be used to help improve turbine or park efficiency. For example, power performance verifications for individual turbines can now be based on the nacelle anemometer with suitable nacelle transfer functions (NTFs) (International Electrotechnical Commission, 2013). Nacelle measurements can also provide critical input for wind farm production optimization (Fleming et al., 2016). With sufficiently accurate NTFs, these data can pro- 


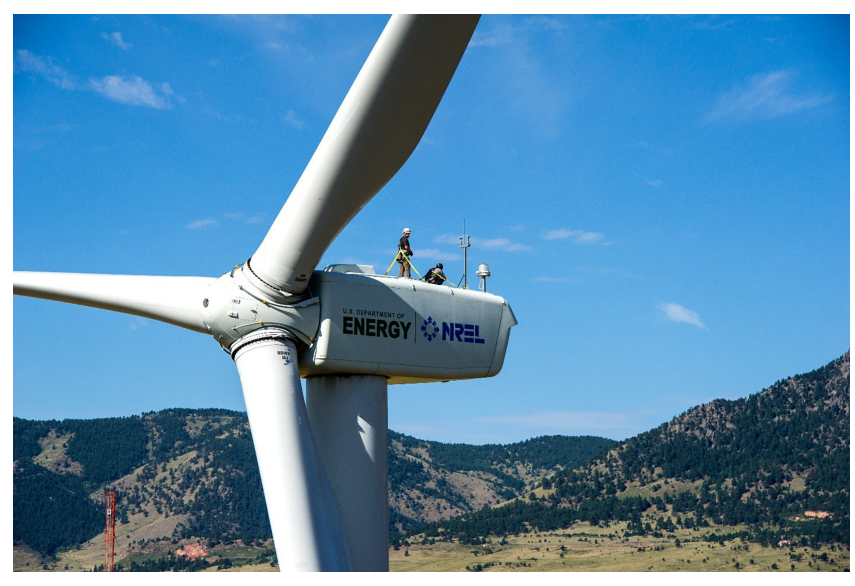

Figure 1. GE $1.5 / 77$ sle turbine at the National Wind Technology Center. Photo credit: Dennis Schroeder, NREL (image gallery number 29611).

vide a valuable, extensive, and continuous source of turbinespecific performance information.

Power performance validation has traditionally relied on hub-height wind speed observations from a meteorological (met) tower upwind of a turbine (Link and Santos, 2004; IEC, 2015). The IEC (2015) standards require a met tower to be placed at the turbine location prior to turbine erection (the so-called "site calibration" procedure) for a power performance test to be considered valid (of sufficiently low total uncertainty) in complex terrain. However, it is not feasible to erect site calibration met towers after the turbine has been erected. Furthermore, even if site calibration is not required because a site is in simple terrain, tower erection is timeconsuming and unrealistic to complete for every turbine at a given park. These factors motivate exploration of the use of nacelle-mounted anemometers to provide wind speed data for power performance validation.

Several studies have found that nacelle anemometer measurements can be adjusted by the use of transfer functions between an upwind hub-height measurement and the nacellemounted anemometer measurement (Antoniou and Pedersen, 1997; Hunter et al., 2001, Smith et al., 2002; Smaïli and Masson, 2004). The IEC (2013) standard now allows the use of nacelle-mounted anemometers to verify power curves based on these transfer functions, or fitted functions of correction factors between upwind hub-height wind speed (UHWS) measurements and nacelle-mounted anemometer wind speed (NAWS) measurements. Quantifying these transfer functions requires that upwind measurements be available at some point post-construction. However, once transfer functions are calculated for a site, the tower can be taken down and the transfer functions used to correct the nacelle measurements for future performance testing.

An empirical NTF may not result in a linear relationship between the UHWS and NAWS. In fact, Antoniou and Ped- ersen (1997) found that the transfer functions fit well with a fifth-order polynomial curve. Hunter et al. (2001) similarly found a nonlinear relationship and that a linear regression would overestimate the wind speed between 6 and $11 \mathrm{~m} \mathrm{~s}^{-1}$ and underestimate the wind speed at wind speeds less than $4 \mathrm{~m} \mathrm{~s}^{-1}$ and greater than $16 \mathrm{~m} \mathrm{~s}^{-1}$. Smith et al. (2002) found a linear relationship with the exception of wind speeds below cut-in and wind speeds around about $15 \mathrm{~m} \mathrm{~s}^{-1}$.

In previous work, the relationship between UHWS measurements and NAWS measurements has been found to depend on multiple factors, including rotor and turbine control settings such as blade pitch angle and inflow angle, the use of vortex generators, yaw error, terrain, flow induction, calibration of the anemometer, and nacelle height and position (Antoniou and Pedersen, 1997; Dahlberg et al., 1999; Smith et al., 2002; Smaïli and Masson, 2004; Frandsen et al., 2009; Zahle and Sørensen, 2011).

The roles of inflow turbulence and atmospheric stability in NTFs have not yet been explored. However, previous work on power performance and annual energy production (AEP) does acknowledge the role of atmospheric stability, wind shear, and turbulence intensity (TI) in inducing deviations in power from the manufacturer power curve (MPC) (e.g., Sumner and Masson, 2006; Antoniou et al., 2009; Rareshide at el., 2009; Wagenaar and Eecen, 2011; Wharton and Lundquist, 2012; Vanderwende and Lundquist, 2012; St. Martin et al., 2016).

In this study, we quantify the effect of NTF-corrected nacelle anemometer measurements on the AEP and investigate the influence of different atmospheric stability and turbulence regimes on these NTFs. In Sect. 2, we briefly summarize our data set, which includes upwind and nacelle-based measurements, as well as our data analysis methods, which include filtering based on turbine operation, and definitions of the stability and turbulence regimes. We present results of AEP calculations together with results of separate NTFs for different stability and turbulence regimes in Sect. 3. In Sect. 4 we summarize conclusions about the effect of the NTF on the AEP in addition to the effects of atmospheric stability and inflow turbulence on the NTFs.

\section{Data and methods}

\subsection{Meteorological and turbine data}

For this analysis, we use 2.5 months of data collected at the US Department of Energy (DOE) National Wind Technology Center (NWTC) at the National Renewable Energy Laboratory (NREL) during the winter (29 November 2012 through 14 February 2013). We use 10 min-averaged turbine supervisory control and data acquisition (SCADA) data from a General Electric (GE) 1.5 MW turbine (GE 1.5/77sle; Fig. 1), with a cut-in wind speed of $3.5 \mathrm{~m} \mathrm{~s}^{-1}$, rated wind speed of $14 \mathrm{~m} \mathrm{~s}^{-1}$, and cut-out wind speed of $25 \mathrm{~m} \mathrm{~s}^{-1}$. A map of the site can be found in St. Martin et al. (2016) (Fig. 1). See Men- 
Table 1. Mounting heights of instruments on the $135 \mathrm{~m}$ met tower.

\begin{tabular}{ll}
\hline Instrument & Mounting heights (m) \\
\hline Cup anemometer & $3,10,30,38,55,80,87,105,122,130$ \\
Wind vane & $3,10,38,87,122$ \\
3-D sonic anemometer & $15,41,61,74,100,119$ \\
Barometric pressure sensor & 3 \\
Precipitation sensor & 3 \\
Temperature sensor & $3,38,87$ \\
Dew point temperature sensor & $3,38,87,122$ \\
\hline
\end{tabular}

doza et al. (2015) for power performance test results from the DOE GE 1.5 along with instrument and site calibration information.

Upwind data include $1 \mathrm{~Hz}$ measurements of wind speed and direction averaged to $10 \mathrm{~min}$ from a Renewable NRG Systems (NRG) Leosphere Windcube v1 vertically profiling Doppler lidar (2.7 rotor diameters (D) upwind; $208 \mathrm{~m}$ ) and 10 and $30 \mathrm{~min}$ averages from a $135 \mathrm{~m}$ met tower $(2.0 \mathrm{D}$ upwind; $154 \mathrm{~m}$ ). Volumetric-averaged wind speeds and directions are measured by the lidar every $20 \mathrm{~m}$, from $40 \mathrm{~m}$ to $220 \mathrm{~m}$. Comparison of the lidar wind profiles to those from the met tower suggest that the lidar data at this site suffered from inhomogeneities as a result of complex flows (Bingöl et al., 2009; Rhodes and Lundquist, 2013; Lundquist et al., 2015). Thus, the majority of this paper will focus on the results of the analysis using the tower data. On the met tower, cup anemometers placed at $3,10,30,38,55,80,87,105,122$, and $130 \mathrm{~m}$ measure wind speed; vanes placed at $3,10,38,87$, and $122 \mathrm{~m}$ measure wind direction; and three-dimensional (3-D) sonic anemometers placed at 15, 41, 61, 74, 100, and $119 \mathrm{~m}$ measure all three components of the wind as well as sonic temperature, which is used to calculate momentum and heat fluxes (Table 1). Barometric pressure and precipitation amounts are measured at $3 \mathrm{~m}$; temperature is measured at 3 , 38 , and $87 \mathrm{~m}$; and dew point temperature is measured at 3,38 , 87, and 122 m (Table 1). See Fig. 2 in St. Martin et al. (2016) for a schematic of the tower.

As discussed in St. Martin et al. (2016), meteorological and turbine data are filtered for quality assurance. Data are only considered during time periods when the turbine is operating and wind direction indicates the turbine is located downwind of the lidar and met tower $\left(235-315^{\circ}\right)$. As the turbine data from the SCADA system are available in $10 \mathrm{~min}$ increments, variability in the turbine parameters on a shorter timescale cannot be discerned. However, we filter for normal turbine operation based on curtailment using generator speed set point for wind speeds greater than $5.5 \mathrm{~m} \mathrm{~s}^{-1}$, whereas for wind speeds less than $5.5 \mathrm{~m} \mathrm{~s}^{-1}$, we discard data when the turbine is not grid-connected and is faulted (Fig. 6 in St. Martin et al., 2016).

Lastly, the nacelle-reported wind speeds used in this analysis have been subjected to a simple, linear-regression transfer function before the retrieval from the SCADA system around the DOE GE 1.5sle turbine. This linear regression function, built into the SCADA system by the turbine manufacturer, effectively translates the raw signal from the cup anemometer to wind speed and is not unlike a transfer function provided by an anemometer manufacturer. We see the uncertainty of this built-in transfer function as an advantage to our analysis as a typical wind plant operator would only have access to similar data.

\subsection{AEP calculations}

To simulate a scenario in which a wind plant operator only has nacelle-based measurements and no upwind tower or remote-sensing measurements, we calculate an AEP (as described in Sect. 9.3 of IEC 61400-12-2, 2013) using only nacelle winds to compare to an AEP calculated with upwind met tower $80 \mathrm{~m}$ winds. We then correct the nacelle-based measurements with NTFs and calculate AEP based on these results for comparison as well. Although data for this analysis only span 2.5 months in the wintertime at the NWTC during the 2012-2013 season, we calculate AEPs using the total number of hours in an entire year to show values close to a representative AEP value. A sample wind distribution using Weibull distribution parameters representative of the data set (scale parameter: $\lambda=10.04 \mathrm{~m} \mathrm{~s}^{-1}$, shape parameter: $k=2.63$; figure not shown) is used in these calculations as suggested by IEC (2015) for a site-specific AEP. We note that these parameters, based on 2.5 months in the high wind season at this site, are not actually representative of the entire year. However, as noted in other analyses of this test site (Clifton and Lundquist, 2012; Clifton et al., 2013), this site would not be chosen for wind development given the long summer season with little or no wind. We emphasize that this approach is not meant to suggest actual AEPs for this site, but to explore the sensitivity of AEP calculations at sites reasonable for wind development.

\subsection{Stability metrics}

We calculate Bulk Richardson numbers $\left(R_{\mathrm{B}}\right)$, Obukhov lengths $(L)$, and power-law exponents $(\alpha)$ and use these as stability metrics for these data. Using wind speed and temperature differences between surface and upper tip (3 and $122 \mathrm{~m}$, respectively) tower measurements, we calculate 10 min values of $R_{\mathrm{B}}$ to compare the buoyant production of turbulence to the mechanical production of turbulence (Stull, 1988) as

$R_{\mathrm{B}}=\frac{g \Delta T \Delta z}{\bar{T} \Delta U^{2}}$,

where $g$ is the gravitational constant, $\Delta T$ is the change in temperature across $\Delta z, \bar{T}$ is the mean temperature across $\Delta z$, and $\Delta U$ is the change in horizontal wind speed across $\Delta z$. Humidity is not considered in this formulation of the Bulk Richardson number. 
Using near-surface flux measurements at $15 \mathrm{~m}$ (within the surface layer) as well as surface temperature and humidity measurements linearly interpolated to $15 \mathrm{~m}$, we calculate 30 min values of $L$ to estimate the height at which the buoyant production of turbulence dominates the mechanical production of turbulence (Stull, 1988) as

$L=-\frac{u_{*}^{3}}{k g} \frac{T_{\mathrm{v}}}{\overline{w^{\prime} T_{\mathrm{s}}^{\prime}}}$,

where $u_{*}$ is the friction velocity, $k$ is the von Kármán constant, $T_{\mathrm{v}}$ is the virtual temperature, $w^{\prime}$ is the vertical wind speed fluctuation, and $T_{\mathrm{s}}^{\prime}$ is the sonic temperature fluctuation.

Using horizontal wind speeds as measured by cup anemometers at 38 and $122 \mathrm{~m}$ (lower tip and upper tip of the rotor disk), we calculate $10 \mathrm{~min}$ values of $\alpha$ to quantify the wind speed vertical profile across the rotor disk as

$\alpha=\frac{\log \frac{U_{2}}{U_{1}}}{\log \frac{z_{2}}{z_{1}}}$,

where $U_{2}$ is the wind speed at height $z_{2}$ and $U_{1}$ is the wind speed at height $z_{1}$.

Though some previous studies combine metrics to define stability (Vanderwende and Lundquist, 2012), the three atmospheric stability metrics discussed here are treated separately with regard to the NTFs because of slight differences between their definitions of unstable and stable conditions (see Fig. 11 in St. Martin et al., 2016). These differences may be attributed to distinctions between each approach in defining atmospheric stability, a difference in averaging period, heights of the measurements used in the calculations, or how $R_{\mathrm{B}}$ and $L$ use wind speed and temperature measurements to define stability, whereas $\alpha$ uses only wind speed measurements.

Furthermore, we calculate TI and turbulence kinetic energy (TKE) to provide turbulence metrics and estimate the effect of hub-height inflow turbulence on the NTFs. Using $80 \mathrm{~m}$ wind speed measurements from the met tower, we calculate $10 \mathrm{~min}$ values of TI, or the standard deviation of the horizontal wind speed normalized by the average horizontal wind speed at hub height. Using $74 \mathrm{~m}$ wind measurements from a 3-D sonic anemometer on the tower, we calculate 30 min values of TKE per unit mass, or the sum of the variances of the components of the wind divided by 2 . Note that after filtering out spikes in the raw $74 \mathrm{~m}$ sonic anemometer data, only about $36730 \mathrm{~min}$ TKE values remain $(183.5 \mathrm{~h}$ ) and the fewer number of data points likely affects the statistical significance of the NTFs for different TKE regimes. Regimes of TI, TKE, and $\alpha$ are determined by splitting the distributions of each parameter roughly into thirds. Regimes of $R_{\mathrm{B}}$ are similarly determined, as in Aitken et al. (2014) and St. Martin et al. (2016), and uncertainty in the $R_{\mathrm{B}}$ values calculated from propagation of instrument accuracy ensures that the regimes are wide enough. Stability regimes based on $L$ are similar to those defined by Muñoz-Esparza (2012). Regimes or classifications for these stability and turbulence parameters are defined in Table 2 and described in detail in St. Martin et al. (2016), along with more detailed descriptions of the data from the lidar, tower, and turbine, as well as filtering methods.

\section{Results}

To explore the variability in the NTF, we calculate specific NTFs filtered by atmospheric stability metrics, TI, and TKE. We investigate filters that have either previously been found to affect the transfer function or are suspected to have an effect on the transfer functions based on power curve studies (e.g., St. Martin et al., 2016). Additionally, we explore the effects of yaw error and wind veer and distributions of these variables, but, as in St. Martin et al. (2016), yaw error and wind veer do not seem to impact either the power curves or the NTFs at this site and are therefore not shown.

\subsection{Preliminary NTFs}

A general NTF (Fig. 2a) compares the tower $80 \mathrm{~m}$ wind speed to the nacelle-reported wind speed using all data that pass the wind speed, wind direction, and normal operation criteria defined in Sect. 2.1 and in more detail in Sect. 3.2 and 3.3 in St. Martin et al. (2016). As a fifth-order polynomial fit was found to be suitable for power curve assessment in previous work by Antoniou and Pedersen (1997) and Hunter et al. (2001), we also apply this type of fit to the wind speeds in this work to estimate an empirical transfer function between $80 \mathrm{~m}$ tower wind speed measurements and nacellemounted anemometer wind speed measurements (Fig. 2a). The $r$-squared value of the fifth-order polynomial fit to the data is 0.9912 , which means the fit line predicts $99.12 \%$ of the variance in the tower data. The RMSE of the fifth-order polynomial fit is $0.3615 \mathrm{~m} \mathrm{~s}^{-1}$. After correcting the nacellemeasured wind speeds using this NTF, deviations between the corrected nacelle wind speed and the tower $80 \mathrm{~m}$ wind speeds (Fig. 2b) vary between -0.2 and $0.2 \mathrm{~m} \mathrm{~s}^{-1}$ throughout all wind speed bins between cut-in and cut-out wind speed.

Based on the small coefficients of the third, fourth, and fifth orders of the fit in Fig. 2a, a fifth-order polynomial may be unnecessarily complex. Therefore, a second-order polynomial fit is also calculated to estimate an empirical transfer function. The $r$-squared value of the second-order polynomial fit with the data is also very high, 0.9909 (Fig. 3a). The RMSE of the second-order polynomial fit is $0.3680 \mathrm{~m} \mathrm{~s}^{-1}$. After correcting the nacelle-measured wind speeds using this NTF, deviations between the corrected nacelle wind speed and the tower $80 \mathrm{~m}$ wind speeds, shown in Fig. 3b, vary from about -0.3 to $0.2 \mathrm{~m} \mathrm{~s}^{-1}$ at a wind speed less than about $22 \mathrm{~m} \mathrm{~s}^{-1}$ but grow to about $0.8 \mathrm{~m} \mathrm{~s}^{-1}$ at higher wind speeds. Though there are fewer data points at these higher wind speed bins, this larger deviation of the second-order 

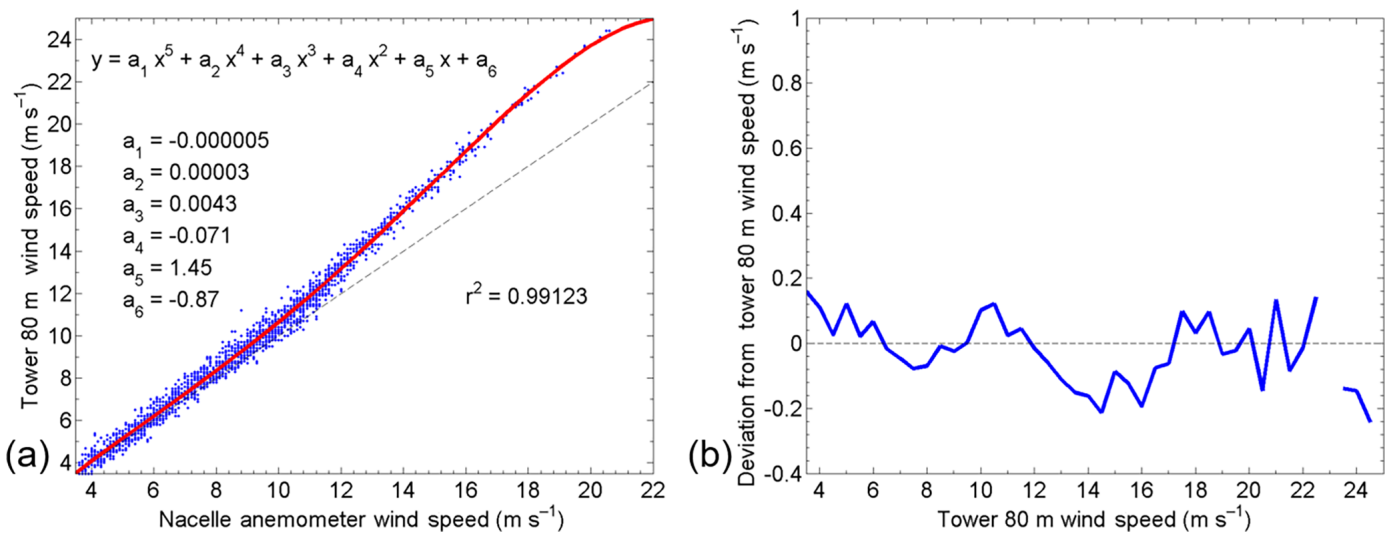

Figure 2. Comparison of upwind wind speeds with nacelle anemometer wind speeds: (a) scatter is the upwind tower $80 \mathrm{~m}$ wind speed versus nacelle wind speed. The red line is the fifth-order polynomial fit and empirical transfer function between the tower $80 \mathrm{~m}$ observations and the nacelle-mounted anemometer observations. The dashed line is $1: 1$. (b) Average deviation in fifth-order polynomial NTF-corrected nacelle-mounted anemometer wind speed from tower $80 \mathrm{~m}$ wind speed versus tower $80 \mathrm{~m}$ wind speed. The dashed line indicates a $0 \mathrm{~m} \mathrm{~s}$ change. The figure includes data filtered for the tower $80 \mathrm{~m}$ wind speeds between 3.5 and $25.0 \mathrm{~m} \mathrm{~s}^{-1}, 87 \mathrm{~m}$ wind directions between 235 and $315^{\circ}$, and for normal turbine operation.

Table 2. Defined stability and turbulence regimes.

\begin{tabular}{lrrrrr}
\hline Regime & $R_{B}$ & $L(\mathrm{~m})$ & $\alpha$ & $\mathrm{TI}(\%)$ & $\mathrm{TKE}\left(\mathrm{m}^{2} \mathrm{~s}^{-2}\right)$ \\
\hline Low & $R_{\mathrm{B}}<-0.03$ & $-1000<L \leq 0$ & $\alpha<0.11$ & $\mathrm{TI}<15$ & $\mathrm{TKE}<3.0$ \\
Medium & $-0.03<R_{\mathrm{B}}<0.03$ & $0 \leq L<1000$ & $0.11<\alpha<0.17$ & $15<\mathrm{TI}<20$ & $3.0<\mathrm{TKE}<6.5$ \\
High & $R_{\mathrm{B}}>0.03$ & $|L| \geq 1000$ & $\alpha>0.17$ & $\mathrm{TI}>20$ & $\mathrm{TKE}>6.5$ \\
\hline
\end{tabular}

NTF-corrected wind speeds from the upwind wind speeds at higher wind speeds suggests that a fifth-order polynomial NTF is unnecessary until high wind speeds are considered.

Both transfer functions for this data set (Figs. 2a, 3a) are close to linear at low wind speeds but nonlinear just before rated speed $\left(14 \mathrm{~m} \mathrm{~s}^{-1}\right)$, hence the higher-order polynomial fits. This behavior suggests that at wind speeds below about $9 \mathrm{~m} \mathrm{~s}^{-1}$, the nacelle anemometer measurement closely corresponds to the upwind wind speed. Above this wind speed threshold, however, the nacelle anemometer underestimates the upwind wind speed by almost $2 \mathrm{~m} \mathrm{~s}^{-1}$ around rated speed to about $4 \mathrm{~m} \mathrm{~s}^{-1}$ at upwind wind speeds near $20 \mathrm{~m} \mathrm{~s}^{-1}$; higher ambient wind speeds are associated with more significant slow downs around the nacelle.

Comparison of the NTF developed from the upwind tower measurements and the NTF developed from the upwind lidar measurements (Fig. 4a) emphasizes that the lidar measurements exhibit greater variability ranging over all relevant wind speeds. The variability in the lidar measurements caused by the inhomogeneity of the flow suggests that the tower measurements are more reliable for calculating power curves and transfer functions at this particular site, which is known to experience complex and inhomogeneous flow (Aitken et al., 2014). Despite the larger variability in the lidar data set for both the transfer function (Fig. 4a) and deviations between the corrected nacelle wind speed and the upwind wind speeds (Fig. 4b), both transfer functions in Fig. 4a show linearity at lower wind speeds and nonlinearity at higher wind speeds.

To try to quantitatively explain this change in the transfer function from linear to nonlinear and to connect with possible flow blockage behind the rotor and along the nacelle, the non-dimensional Froude number (Stull, 1988) for flow around the nacelle is calculated. Froude numbers are investigated during stable conditions using measurements from the tower at the surface and around hub height and using a range of length scales from 1 to $10 \mathrm{~m}$ to represent the length and width of the nacelle. However, distinctions between these two wind speed regions could not be seen in these calculations as Froude numbers were found to be positive and increase with increasing wind speed.

Additionally, because the transfer functions become nonlinear between cut-in wind speed and rated speed, the transfer function may be impacted by turbine operations in that region of the power curve, possibly because of root vortices (Whale et al., 2000). Just below rated speed, the blades begin to pitch forward to maintain rated generator speed, thus allowing power production to remain near rated power (Fig. 5). This "feathering" of the blades changes the flow around the blades and therefore the wind that affects the nacellemounted anemometer measurement. Though this hypothesis cannot be further investigated within this campaign as 

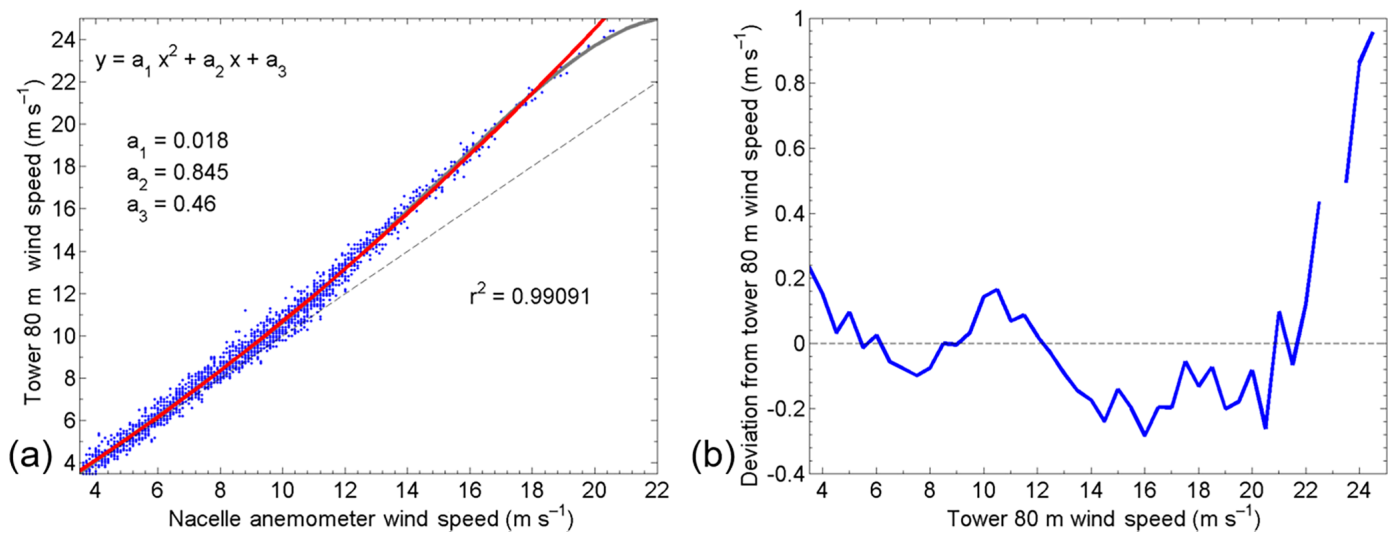

Figure 3. Comparison of upwind wind speeds with nacelle anemometer wind speeds. The red line in panel (a) is the second-order polynomial fit and empirical transfer function between the tower $80 \mathrm{~m}$ observations and the nacelle-mounted anemometer observations. The gray line in panel (a) is the fifth-order polynomial fit. (b) Average deviation in the second-order polynomial NTF-corrected nacelle-mounted anemometer wind speed from tower $80 \mathrm{~m}$ wind speed versus tower $80 \mathrm{~m}$ wind speed is shown.
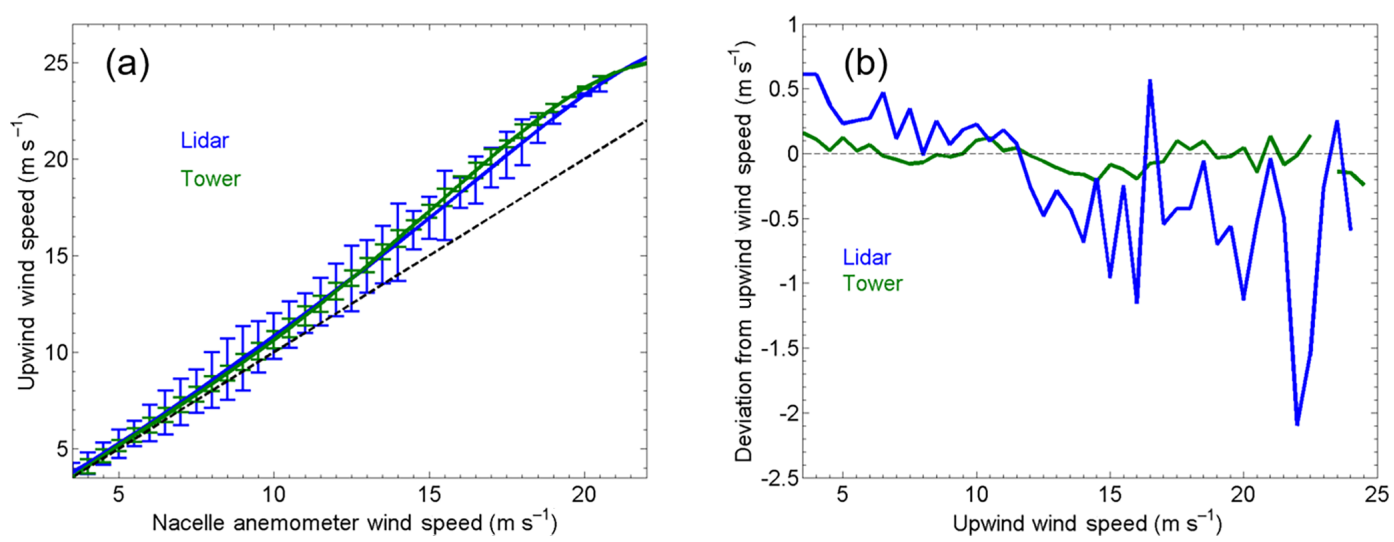

Figure 4. (a) NTFs calculated employing fifth-order polynomial fits using tower hub-height data (green) and lidar hub-height data (blue). Envelopes represent $\pm \sigma$ of the data within the same bins as the bins the NTFs are calculated with. Includes data filtered for tower $80 \mathrm{~m}$ wind speeds between 3.5 and $25.0 \mathrm{~m} \mathrm{~s}^{-1}, 87 \mathrm{~m}$ wind directions between 235 and $315^{\circ}$, and for normal turbine operation. The dashed line is $1: 1$; panel (b) shows the average deviation in NTF-corrected nacelle-mounted anemometer wind speed from tower $80 \mathrm{~m}$ wind speed (green) and lidar $80 \mathrm{~m}$ wind speed (blue) versus tower $80 \mathrm{~m}$ wind speed. The dashed line indicates a $0 \mathrm{~m} \mathrm{~s}^{-1}$ change.

higher-resolution data from the SCADA system are unavailable, this does make a compelling argument for installing 3$\mathrm{D}$ sonic anemometers on nacelles so that vertical velocity can be measured to further understand the 3-D wind structures behind the rotor and along the nacelle and how these flow structures change as inflow wind speed increases.

\subsection{Annual energy production and NTFs}

It is important to understand the characteristics of the NTF and how it changes with wind speed, as this under-estimation of the ambient wind speed, especially at wind speeds in which the growth in power production with wind speed is the most significant, could result in a significant overestimation of AEP in power performance verification.
With no NTF correction applied (aside from the transfer function that is built into the SCADA system by the manufacturer), the AEP calculated with nacelle winds (AEP_nacelle) overestimates the AEP calculated with $80 \mathrm{~m}$ tower winds (AEP_upwind) by $5.96 \%$ (Table 3). This overestimation of AEP is expected as the nacelle anemometer consistently underestimates the upwind wind speed, which leads to the misrepresentation of higher power output at lower wind speeds, effectively shifting the entire power curve to the left, and therefore leading to a higher AEP.

The use of the NTF to correct the nacelle anemometer measurements reduces the AEP error significantly (Table 3). With the application of the fifth-order polynomial NTF (AEP_NTF5th), AEP_NTF5th underestimates AEP_upwind by only $0.003 \%$, whereas with the application of the secondorder polynomial NTF (AEP_NTF2nd), AEP_NTF2nd un- 
Table 3. Top row shows Annual energy production (AEP) in megawatt hours per year calculated using upwind tower measurements (AEP_upwind), nacelle winds (AEP_nacelle), corrected nacelle winds using the NTF calculated with a fifth-order polynomial (AEP_NTF5th), and corrected nacelle winds using the NTF calculated with a second-order polynomial (AEP_NTF2nd). Bottom row shows AEP in percentage calculated as a percentage of AEP_upwind.

\begin{tabular}{lrrrr}
\hline & AEP_upwind & AEP_nacelle & AEP_NTF5th & AEP_NTF2nd \\
\hline AEP $(\mathrm{MWh} / \mathrm{y})$ & $7,479.3$ & $7,924.7$ & 7.479 .1 & $7,465.8$ \\
$\%$ of tower winds & 100.00 & 105.96 & 100.00 & 99.82 \\
\hline
\end{tabular}

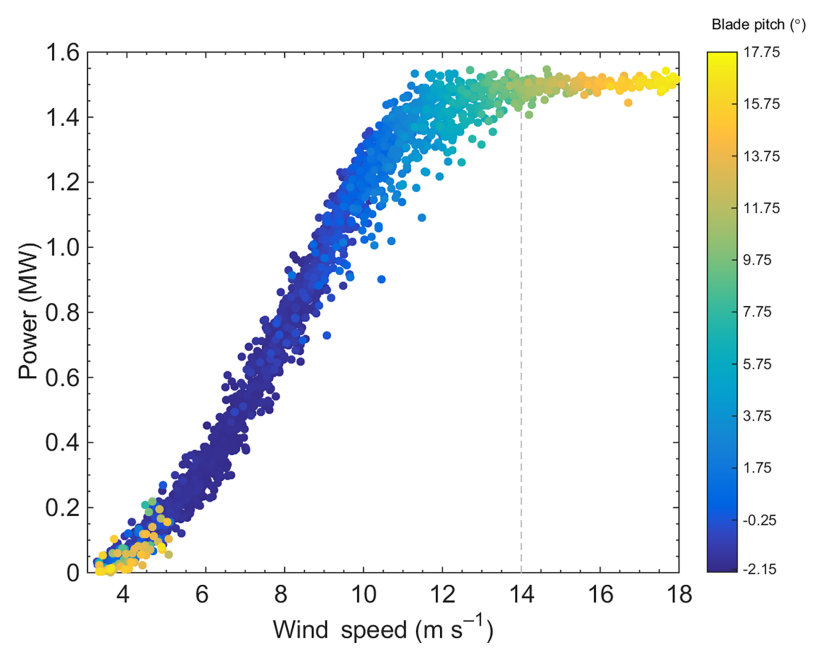

Figure 5. Scatter power curve using $80 \mathrm{~m}$ tower winds after filtering for wind speeds between 3.5 and $25 \mathrm{~m} \mathrm{~s}^{-1}$, wind directions between 235 and $315^{\circ}$, and for normal turbine operation. Colors of the scatter points correspond to blade pitch angles. The dashed gray line marks rated speed.

derestimates AEP_upwind by $0.18 \%$. Therefore, using either the fifth-order polynomial or the second-order polynomial for the NTF results in an AEP similar to that of an AEP calculated with upwind hub-height winds, though both lead to a slight underestimation.

\subsection{Atmospheric stability effects of NTFs}

The value of atmospheric-stability segregation for NTFs seems to depend on how stability is defined. Some statistically significant distinctions in the NTFs for $R_{\mathrm{B}}$-defined unstable and stable cases do emerge (Fig. 6a, Table 4), particularly for wind speeds between 7 and $11 \mathrm{~m} \mathrm{~s}^{-1}$. Closed circles in Fig. 6a represent statistically distinct wind speed bins between the stability classes and are determined by the Wilcoxon rank sum test with a $1 \%$ significance level. Stable cases follow a linear relationship more closely for low and moderate wind speeds (less than $11 \mathrm{~m} \mathrm{~s}^{-1}$ ), whereas unstable cases show more deviation from the $1: 1$ line at wind speeds greater than $8 \mathrm{~m} \mathrm{~s}^{-1}$. This behavior shown by NTFs segregated by $R_{\mathrm{B}}$ suggests that below rated speed in convective conditions, the nacelle anemometer underestimates the am- bient wind speed more than in stable conditions. Conversely, no statistically significant distinctions emerge in the NTFs for $L$-defined stability classes for this site using our data set (Fig. 7a, Table 4). Distinctions in the NTFs for $\alpha$-defined cases (Fig. 8a, Table 5) emerge only around $13.5 \mathrm{~m} \mathrm{~s}^{-1}$ much closer to rated speed - and stable cases underestimate the upwind wind speed more than unstable cases.

We apply the NTFs to the nacelle anemometer measurements to evaluate the deviations from the upwind met tower data (Figs. 6b, 7b, and 8b); however, the results show no consistency or systematic distinctions between stability metrics, stability classes, or wind speed.

\subsection{Turbulence effects on NTFs}

The hypothesis that convectively driven mixing and turbulence causes underestimation by the nacelle-mounted anemometer is further supported in the NTFs segregated by TI (Fig. 9a, Table 6) and TKE classes (Fig. 9b, Table 6). Distinctions between unstable and stable cases in the transfer functions for wind speeds between 5.5 and $12 \mathrm{~m} \mathrm{~s}^{-1}$ are also apparent when the transfer functions are segregated by TI class (Fig. 9a) and for wind speeds around $12 \mathrm{~m} \mathrm{~s}^{-1}$ when the transfer functions are segregated by TKE class (Fig. 9b). Periods of relatively high TI and TKE result in greater underestimations of the wind speed by the nacelle anemometer from just above cut-in wind speed to about $12 \mathrm{~m} \mathrm{~s}^{-1}$.

Corrections to the nacelle wind speeds using NTFs based on atmospheric turbulence show lower deviations from the ambient wind speed below rated speed and larger deviations from the ambient wind speed after rated speed for high TI cases. However, similar to the results in Figs. 6b, 7b, and 8b, Fig. 9c, d also show inconsistencies between deviations from the upwind speed for the different turbulence metrics and regimes.

\subsection{Discussion}

We speculate that at wind speeds below rated, mixing in the atmosphere during more convective conditions, as well as the turbine interaction with these turbulent eddies, may result in additional motion that exaggerates blockage effects by the rotor and nacelle and causes underestimation by the nacellemounted anemometer. We suspect that rotor response is lagging in more convective and turbulent conditions as the tur- 

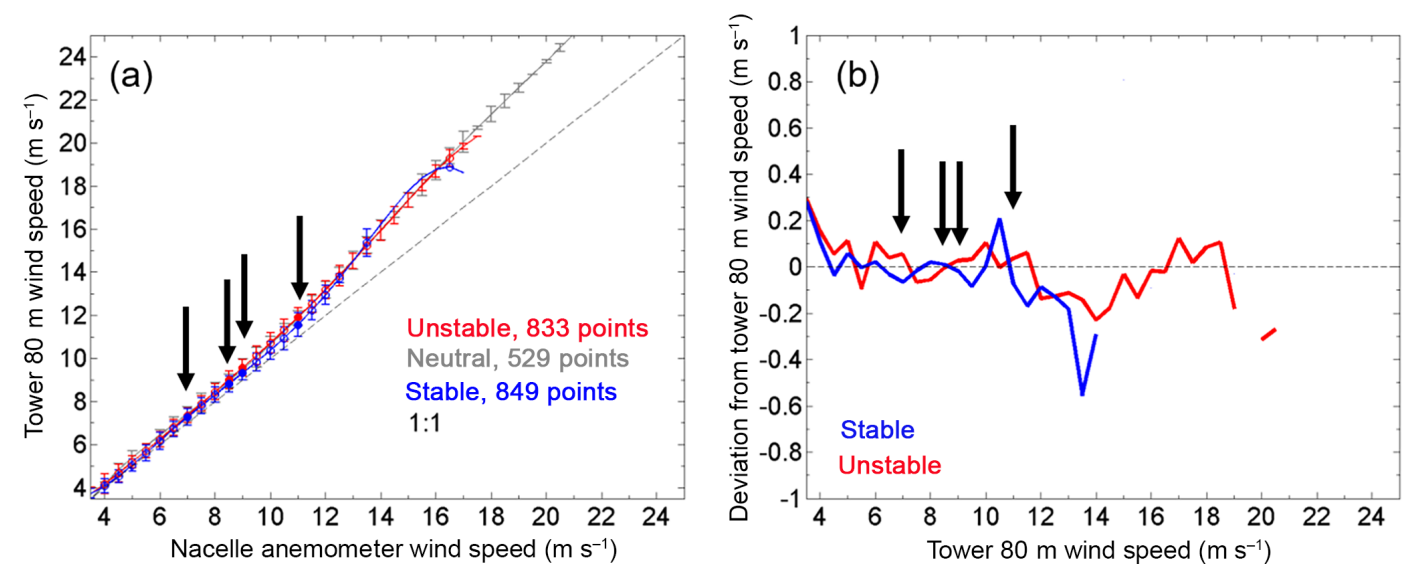

Figure 6. (a) Tower $80 \mathrm{~m}$ NTFs calculated using fifth-order polynomial fits with stability regimes based on $R_{\mathrm{B}}$. Error bars represent $\pm \sigma$ of the data within the same bins as the bins with which the NTFs are calculated. Statistically distinct differences within each wind speed bin between the stability classes are determined by the Wilcoxon rank sum test with a $1 \%$ significance level and denoted by closed circles. Black arrows point towards statistically distinct bins. The figures include data filtered for tower $80 \mathrm{~m}$ wind speeds between 3.5 and $25.0 \mathrm{~m} \mathrm{~s} \mathrm{~s}^{-1}$, $87 \mathrm{~m}$ wind directions between 235 and $315^{\circ}$, and for normal turbine operation. (b) Average deviation in NTF-corrected nacelle-mounted anemometer wind speed from tower $80 \mathrm{~m}$ wind speed is shown during stable conditions (blue) and during unstable conditions (red) versus tower $80 \mathrm{~m}$ wind speed with stability regimes based on $R_{\mathrm{B}}$. The dashed line indicates a $0 \mathrm{~m} \mathrm{~s}^{-1}$ change.
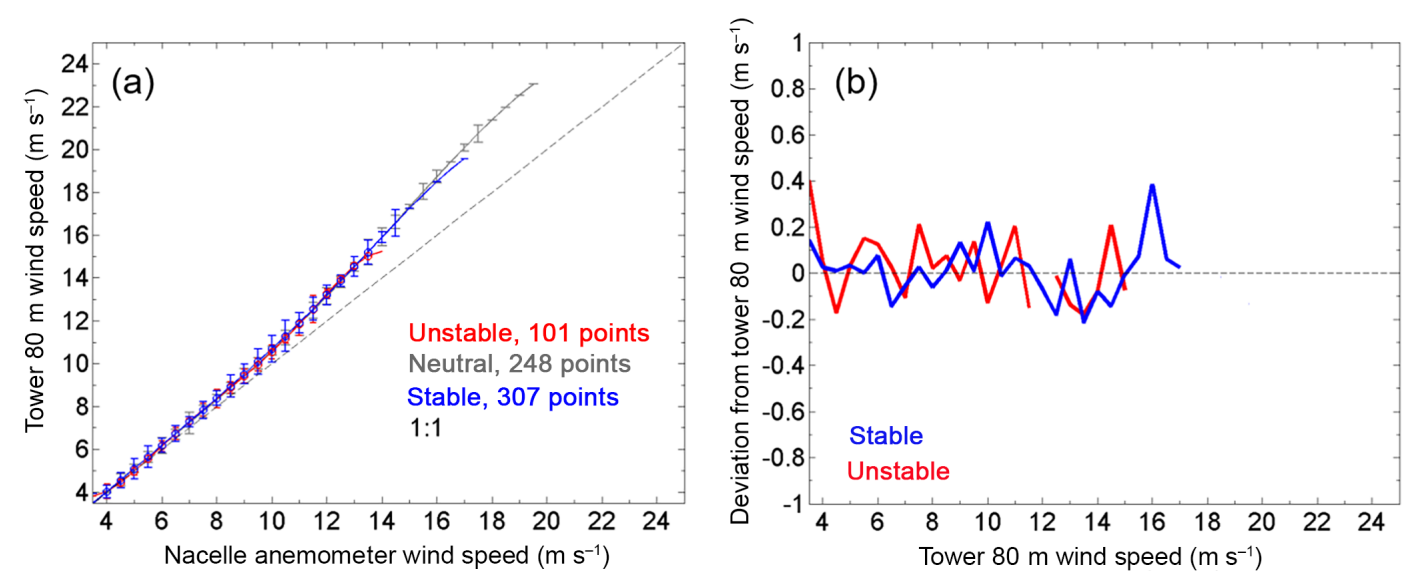

Figure 7. (a) Tower $80 \mathrm{~m}$ NTFs calculated using fifth-order polynomial fits with stability regimes based on $L$. Error bars represent $\pm \sigma$ of the data within the same bins as the bins with which the NTFs are calculated. Statistically distinct differences within each wind speed bin between the stability classes are determined by the Wilcoxon rank sum test with a $1 \%$ significance level and denoted by closed circles. The figures include data filtered for tower $80 \mathrm{~m}$ wind speeds between 3.5 and $25.0 \mathrm{~m} \mathrm{~s}^{-1}, 87 \mathrm{~m}$ wind directions between 235 and $315^{\circ}$, and for normal turbine operation. (b) Average deviation in NTF-corrected nacelle-mounted anemometer wind speed from tower $80 \mathrm{~m}$ wind speed is shown during stable conditions (blue) and during unstable conditions (red) versus tower $80 \mathrm{~m}$ wind speed with stability regimes based on $L$. The dashed line indicates a $0 \mathrm{~m} \mathrm{~s}^{-1}$ change.

bine responds more quickly to drops in wind speed. Therefore, during more turbulent conditions, it is possible that lower rotor efficiency influences flow induction and thus the wind speeds measured on the back of the nacelle. If turbine and rotor efficiencies are lower during periods with convective and more turbulent conditions, it may then be surmised that less momentum passes through the rotor and along the nacelle. In addition, power curve results from the same data set discussed here (St. Martin et al., 2016) show that during less stable and more turbulent conditions at wind speeds within the ramp-up region of the power curve, more power is produced than during periods of more stable and less turbulent conditions. Power production will also affect the flow induction (Frandsen et al., 2009) and thus the wind speed directly behind the rotor disk: if more energy is extracted by the rotor, the nacelle-mounted anemometer will likely measure lower winds. 

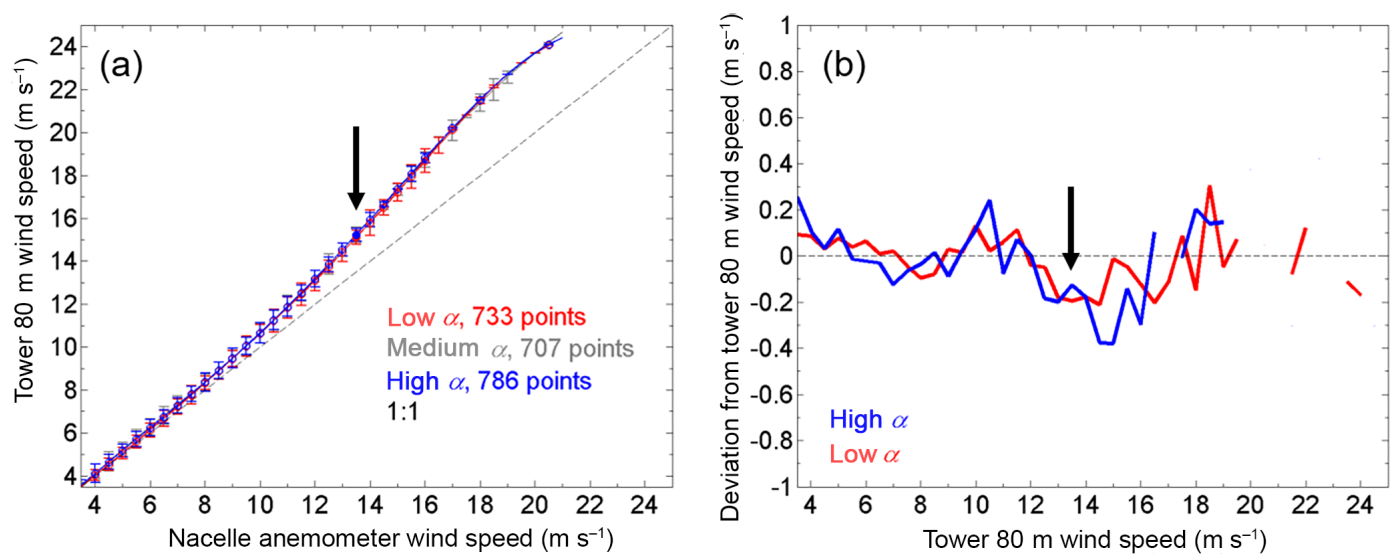

Figure 8. (a) Tower $80 \mathrm{~m}$ NTFs calculated using fifth-order polynomial fits with stability regimes based on $\alpha$. Error bars represent $\pm \sigma$ of the data within the same bins as the bins with which the NTFs are calculated. Statistically distinct differences within each wind speed bin between the stability classes are determined by the Wilcoxon rank sum test with a $1 \%$ significance level and denoted by closed circles. Black arrows point towards statistically distinct bins. The figures include data filtered for tower $80 \mathrm{~m}$ wind speeds between 3.5 and $25.0 \mathrm{~m} \mathrm{~s}{ }^{-1}$, $87 \mathrm{~m}$ wind directions between 235 and $315^{\circ}$, and for normal turbine operation. (b) Average deviation in NTF-corrected nacelle-mounted anemometer wind speed from tower $80 \mathrm{~m}$ wind speed is shown during stable conditions (blue) and during unstable conditions (red) versus tower $80 \mathrm{~m}$ wind speed with stability regimes based on $\alpha$. The dashed line indicates a $0 \mathrm{~m} \mathrm{~s}^{-1}$ change.

Table 4. Coefficients for fifth-order polynomial NTFs for stability metrics.

\begin{tabular}{l|rrr|rrr}
\hline & \multicolumn{3}{|c|}{$R_{B}$} & & \multicolumn{2}{l}{} \\
\hline Regime & Convective & Neutral & Stable & Convective & Neutral & Stable \\
\hline$a_{1}$ & $-6.4141 \times 10^{-5}$ & $3.7809 \times 10^{-5}$ & $-3.0593 \times 10^{-4}$ & $-6.7085 \times 10^{-4}$ & $2.9071 \times 10^{-6}$ & $-3.8242 \times 10^{-5}$ \\
$a_{2}$ & 0.0030 & -0.0025 & 0.0142 & 0.0287 & $-4.4810 \times 10^{-4}$ & 0.0016 \\
$a_{3}$ & -0.0539 & 0.0621 & -0.2473 & -0.4721 & 0.0153 & -0.0245 \\
$a_{4}$ & 0.4628 & -0.6843 & 2.0334 & 3.7194 & -0.1881 & 0.1789 \\
$a_{5}$ & -0.8555 & 4.4391 & -6.8356 & -12.9316 & 2.0185 & 0.4534 \\
$a_{6}$ & 2.9265 & -5.9942 & 11.3853 & 19.7947 & -1.9273 & 0.5361 \\
\hline
\end{tabular}

Table 5. Coefficients for fifth-order polynomial NTFs for the shear exponent.

\begin{tabular}{lrrr}
\hline \multicolumn{3}{c}{$\alpha$} \\
\hline Regime & Convective & Neutral & Stable \\
\hline$a_{1}$ & $-2.3643 \times 10^{-5}$ & $1.4220 \times 10^{-5}$ & $-5.9409 \times 10^{-6}$ \\
$a_{2}$ & 0.0011 & -0.0011 & $7.3499 \times 10^{-5}$ \\
$a_{3}$ & -0.0202 & 0.0301 & 0.0038 \\
$a_{4}$ & 0.1781 & -0.3451 & -0.0689 \\
$a_{5}$ & 0.2889 & 2.7912 & 1.4373 \\
$a_{6}$ & 1.0387 & -3.2175 & -0.7869 \\
\hline
\end{tabular}

\section{Conclusions}

Over 2 months of data from both upwind instruments and nacelle-based instruments are used to quantify general nacelle transfer functions (NTFs) as well as NTFs that vary with atmospheric stability and turbulence parameters. We show that correcting nacelle winds using these NTFs results in more accurate annual energy production (AEP) estimates that are similar to estimates obtained using upwind meteorological (met) tower-based wind speeds. Furthermore, multiple factors have been investigated for their influence on NTFs, including both parameters known to influence wind power production and parameters never before investigated in the context of transfer functions.

We find that fitting the data to a fifth-order polynomial to estimate the NTF results in a slightly higher $r$-squared value and smaller RMSE than fitting to a second-order polynomial. The small differences in the uncertainties between the two methods seem insignificant, as the $r$-squared value of 0.9909 using the second-order polynomial is comparable to the 0.9912 value using the fifth-order fit. However, though the $r$-squared value of the second-order fit is high, after correcting the nacelle winds with the second-order NTF, larger deviations from the upwind tower winds occur than if a fifthorder NTF is used, especially at higher wind speeds.

At wind speeds below $9 \mathrm{~m} \mathrm{~s}^{-1}$, the nacelle anemometer measurement closely corresponds to the upwind wind speed 

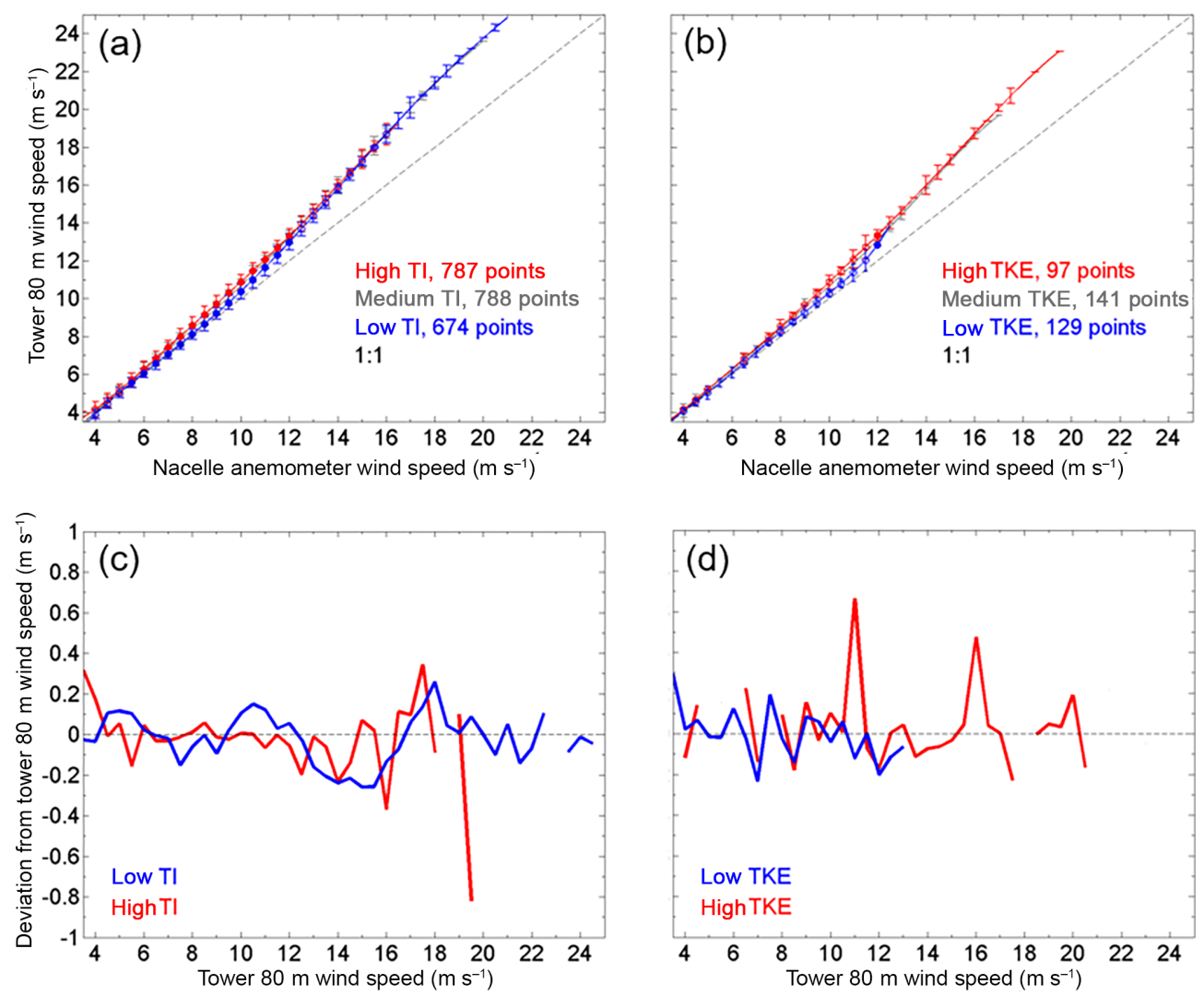

Figure 9. Tower $80 \mathrm{~m}$ NTFs calculated using fifth-order polynomial fits with turbulence regimes based on (a) turbulence intensity (TI) and (b) turbulence kinetic energy (TKE). Error bars represent $\pm \sigma$ of the data within the same bins as the bins with which the NTFs are calculated. Statistically distinct differences within each wind speed bin between the stability classes are denoted by closed circles. Figures include data filtered for tower $80 \mathrm{~m}$ wind speeds between 3.5 and $25.0 \mathrm{~m} \mathrm{~s}^{-1}, 87 \mathrm{~m}$ wind directions between 235 and $315^{\circ}$, and for normal turbine operation. Average deviation in NTF-corrected nacelle-mounted anemometer wind speed from tower $80 \mathrm{~m}$ wind speed is shown during stable conditions (blue) and during unstable conditions (red) versus tower $80 \mathrm{~m}$ wind speed with turbulence regimes based on (c) TI and (d) TKE. The dashed line indicates a $0 \mathrm{~m} \mathrm{~s}^{-1}$ change.

Table 6. Coefficients for fifth-order polynomial NTFs for turbulence metrics.

\begin{tabular}{l|rrr|rrr}
\hline & \multicolumn{3}{|c|}{ TI } & \multicolumn{3}{c}{ TKE } \\
\hline Regime & High & Med & Low & High & Med & Low \\
\hline$a_{1}$ & $-9.0463 \times 10^{-5}$ & $1.5534 \times 10^{-5}$ & $2.3161 \times 10^{-5}$ & $-1.3295 \times 10^{-5}$ & $-6.7464 \times 10^{-5}$ & $4.5266 \times 10^{-4}$ \\
$a_{2}$ & 0.0045 & -0.0012 & -0.0017 & $6.0813 \times 10^{-4}$ & 0.0031 & -0.0156 \\
$a_{3}$ & -0.0842 & 0.0305 & 0.0428 & -0.0103 & -0.0539 & 0.2048 \\
$a_{4}$ & 0.7602 & -0.3409 & -0.4763 & 0.0949 & 0.4418 & -1.2609 \\
$a_{5}$ & -2.1704 & 2.7552 & 3.3911 & 0.6268 & -0.6458 & 4.6488 \\
$a_{6}$ & 5.0077 & -3.2307 & -4.4045 & 0.6460 & 2.3183 & -3.9372 \\
\hline
\end{tabular}

measurement. Above this wind speed threshold, however, the nacelle anemometer underestimates the upwind wind speed, which could result in a significant underestimation of power production and could be perceived as turbine overperformance (or mask turbine underperformance) if not corrected for by a NTF. Additionally, the nonlinear nature of the transfer functions above about $9 \mathrm{~m} \mathrm{~s}^{-1}$ suggests that the transfer function may be impacted by turbine operations near rated speed and how they affect the flow behind the rotor disk and along the nacelle.

The use of NTFs in AEP calculations results in a difference of less than $1 \%$ from the AEP calculated with the upwind met tower wind speed. AEP calculations reveal that an AEP calculated using a fifth-order polynomial correction to the nacelle winds results in a $0.003 \%$ underestimation of the AEP calculated with the upwind wind speed, whereas an 
AEP calculated using a second-order polynomial correction results in a $0.18 \%$ underestimation of the AEP calculated with the upwind wind speed. Both are sizeable improvements over using the uncorrected nacelle wind speed, which leads to a $5.96 \%$ overestimation when compared to the AEP calculated with the upwind wind speed.

Statistically significant distinctions emerge in the transfer functions for unstable and stable cases as defined by the Bulk Richardson number $\left(R_{\mathrm{B}}\right)$, particularly for wind speeds between 9 and $11 \mathrm{~m} \mathrm{~s}^{-1}$. At these wind speeds before rated, in unstable conditions, the nacelle anemometer underestimates the ambient wind speed more often than in stable conditions. Similar but more prominent behavior is found in transfer functions separated by turbulence intensity (TI) and turbulence kinetic energy (TKE) classifications: during periods with relatively high TI and TKE, the nacelle anemometer underestimates the ambient wind speed more than during periods of relatively low TI and TKE, between about 6 and $12 \mathrm{~m} \mathrm{~s}^{-1}$. We speculate that turbine interaction with the mixing in the atmosphere during more convective and turbulent conditions may result in additional motion, thereby exaggerating the blockage by the nacelle and thus underestimation by the nacelle-mounted anemometer.

Distinctions in power curves (Sumner and Masson, 2006; Antoniou et al., 2009; Vanderwende and Lundquist, 2012; Dörenkämper et al., 2014; St. Martin et al., 2016) can lead to a correlation between these distinctions and distinctions in NTFs as well as the idea of validating power performance data with similar atmospheric and operational characteristics with their corresponding power curve in an effort to decrease the amount of uncertainty in power performance testing.

NTFs have recently been accepted for power curve validation under certain circumstances (IEC, 2013). They can also enable the use of nacelle-mounted anemometers for AEP estimates, turbine performance analysis, and data assimilation for improved forecasting (Draxl, 2012; Delle Monache et al., 2013).

Further work could explore how turbine controls and characteristics such as thrust affect the transfer functions. Simulations of flow around the nacelle such as those of Keck (2012) could be expanded to account for variations in atmospheric stability and could be coupled with control software simulators. As Bibor and Masson (2007) suggest, a single transfer function should not be used for every wind plant site and for every atmospheric and operating condition. Several atmospheric and operational conditions and how they affect the transfer functions should be investigated and perhaps combined to provide an algorithm for manufacturers and wind plant operators to use in power performance validation.

Data availability. Data from the M5 tower are available for download at http://wind.nrel.gov/MetData/135mData/M5Twr/.
Competing interests. The authors declare that they have no conflict of interest.

Acknowledgements. The authors express appreciation to the Center for Research and Education in Wind for supporting this work, to Thomas Fischetti and Peter Gregg at GE Renewable Energy for their assistance in turbine data collection and interpretation, and to the reviewers of a previous version of this work. This work was supported by the US Department of Energy under contract no. DE-AC36-08GO28308 with the National Renewable Energy Laboratory. Funding for the work was provided by the DOE Office of Energy Efficiency and Renewable Energy, Wind and Water Power Technologies Office.

Edited by: H. Hangan

Reviewed by: two anonymous referees

\section{References}

Aitken, M. L., Lundquist, J. K., Pichugina, Y. L., and Banta, R. M.: Quantifying wind turbine wake characteristics from scanning remote sensor data, J. Atmos. Ocean. Tech., 31, 765-787, https://doi.org/10.1175/JTECH-D-13-00104.1, 2014.

Antoniou, I. and Pedersen, T. F.: Nacelle Anemometry on a 1MW Wind Turbine, Ris $\varnothing$ National Laboratory, Roskilde, Denmark, 37 pp., 1997.

Antoniou, I., Pedersen, S. M., and Enevoldsen, P. B.: Wind shear and uncertainties in power curve measurement and wind resources, Wind Eng., 33, 449-468, https://doi.org/10.1260/030952409790291208, 2009.

Bibor, E. and Masson, C.: Power Performance via Nacelle Anemometry on Complex Terrain, Wind Energy, Springer Berlin Heidelberg, 43-47, 2007.

Bingöl, F., Mann, J., and Foussekis, D.: Conically scanning LIDAR error in complex terrain, Meteorol. Z., 18, 189-195, https://doi.org/10.1127/0941-2948/2009/0368, 2009.

Clifton, A. and Lundquist, J. K.:Data clustering reveals climate impacts on local phenomena, J. Appl. Meteorol. Clim., 51, 15471557, https://doi.org/10.1175/JAMC-D-11-0227.1, 2012.

Clifton, A., Schreck, S., Scott, G., and Lundquist, J. K.: Turbine inflow characterization at the National Wind Technology Center, J. Sol. Energ.-T. ASME, 135, 031017, https://doi.org/10.1115/1.4024068, 2013.

Dahlberg, J. A., Frandsen, S., Madsen, H. A., Antoniou, I., Pedersen, T. F., Hunter, R., Klug, H., and Albers, A.: Is the nacelle mounted anemometer an acceptable option in performance testing, Proceeding of the European Wind Energy Conference, Nice, 624-637, 1999.

Delle Monache, L., Eckel, F. A., Rife, D. L., Nagarajan, B., and Searight, K.: Probabilistic Weather Prediction with an Analog Ensemble, Mon. Weather Rev., 141, 3498-3516, https://doi.org/10.1175/MWR-D-12-00281.1, 2013.

Dörenkämper, M., Tambke, J., Steinfield, G., Heinemann, D., and Kühn, M.: Atmospheric impacts on power curves of multimegawatt offshore wind turbines, J. Phys. Conf. Ser., 555, 1-11, https://doi.org/10.1088/1742-6596/555/1/012029, 2014. 
Draxl, C.: On the Predictability of Hub Height Winds, DTU Wind Energy PhD-Report, 104 pp., 2012.

Fleming, P. A., Ning, A., Gebraad, P. M. O., and Dykes, K.: Wind plant system engineering through optimization of layout and yaw control, Wind Energy, 19, 329-344, https://doi.org/10.1002/we.1836, 2016.

Frandsen, S., Sørensen, J. N., Mikkelsen, R., Pederesen, T. F., Antoniou, I., and Hansen, K.: The generics of wind turbine nacelle anemometry, Proceedings of European Wind Energy Conference, Marseille, France, 2009.

Hunter, R., Pedersen, T. F., Dunbabin, P., Antoniou, I., Frandsen, S., Klug, H., Albers, A., and Lee, W. K.: European wind turbine testing procedure developments: Task 1: measurement method to verify wind turbine performance characteristics, Ris $\emptyset$ National Laboratory, Roskilde, Denmark, 1-120, 2001.

IEC: 61400-12-2 Ed. 1.0: Wind turbines - Part 12-2: power performance of electricity producing wind turbines based on nacelle anemometry, IEC, Geneva, Switzerland, 2013.

IEC: 61400-12-1 Ed 2.0: Wind turbines - Part 12-1: power performance measurements of electricity producing wind turbines, IEC, Geneva, Switzerland, 2015.

Keck, R. E.: A numerical investigation of nacelle anemometry for a HAWT using actuator disc and line models in CFX, Renew. Energ., 48, 72-84, https://doi.org/10.1016/j.renene.2012.04.004, 2012.

Link, H. F. and Santos, R: International Energy Agency Wind Turbine Round-Robin Test Task: Final Report, NREL, Golden, CO, 31 pp., http://www.nrel.gov/docs/fy04osti/36238.pdf (last access: 24 May 2016), 2004.

Lundquist, J. K., Churchfield, M. J., Lee, S., and Clifton, A.: Quantifying error of lidar and sodar Doppler beam swinging measurements of wind turbine wakes using computational fluid dynamics, Atmos. Meas. Tech., 8, 907-920, https://doi.org/10.5194/amt-8-907-2015, 2015.

Mendoza, I., Hur, J., Thao, S., and Curtis, A.: Power performance test report for the U.S. Department of Energy 1.5-megawatt wind turbine, NREL, Golden, CO, 1-55, http://www.nrel.gov/docs/ fy15osti/63684.pdf (last accessed: 8 May 2016), 2015.

Muñoz-Esparza, D., Cañadillas, B., Neumann, T., and vanBeech, J.: Turbulent fluxes, stability and shear in the offshore environment: mesoscale modelling and field observations at FINO1, J. Renew. Sustain. Energ., 4, 1-16, https://doi.org/10.1063/1.4769201, 2012.

NWTC Information Portal: NWTC 135 m Meteorological Towers Data Repository, https://nwtc.nrel.gov/135mData (last modified: 1 April 2015), last access: 29 May 2017.
Rareshide, E., Tindal, A., Johnson, C., Graves, A.M., Simpson, E., Bleeg, J., Harris, T., and Schoborg, D.: Effects of complex wind regimes on turbine performance, AWEA Windpower 2009 meeting, Chicago, IL, 2009.

Rhodes, M. E. and Lundquist, J. K.: The effect of wind-turbine wakes on summertime US Midwest atmospheric wind profiles as observed with ground-based Doppler LIDAR, Bound.-Lay. Meteorol., 149, 85-103, https://doi.org/10.1007/s10546-013-9834$\mathrm{x}, 2013$.

Smaili, A., and Masson, C.: On the rotor effects upon nacelle anemometry for wind turbines, Wind Energy, 28, 695-714, https://doi.org/10.1260/0309524043729958, 2004.

Smith, B., Link, H., Randall, G., and McCoy, T.: Applicability of Nacelle Anemometer Measurements for Use in Turbine Power Performance Tests, AWEA Windpower, Portland, OR, 2002.

St. Martin, C. M., Lundquist, J. K., Clifton, A., Poulos, G. S., and Schreck, S. J.: Wind turbine power production and annual energy production depend on atmospheric stability and turbulence, Wind Energ. Sci., 1, 221-236, https://doi.org/10.5194/wes-1221-2016, 2016.

Stull, R. B.: An Introduction to Boundary Layer Meteorology, Kluwer Academic Publishers, Netherlands, 1988.

Sumner, J. and Masson, C.: Influence of atmospheric stability on wind turbine power performance curves, J. Sol. Energ.-T. ASME, 128, 531-538, https://doi.org/10.1115/1.2347714, 2006.

Vanderwende, B. and Lundquist, J. K.: The modification of wind turbine performance by statistically distinct atmospheric regimes, Environ. Res. Lett., 7, 1-7, https://doi.org/10.1088/1748-9326/7/3/034035, 2012.

Wagenaar, J. W. and Eecen, P. J.: Dependence of power performance on atmospheric conditions and possible corrections, European Wind Energy Association (EWEA) 2011 conference, Brussels, Belgium, http://www.ecn.nl/docs/library/report/2011/ m11033.pdf (last access: 9 May 2016), 2011.

Whale, J., Andersen, C. G., Bareiss, R., and Wagner, S.: An experimental and numerical study of the vortex structure in the wake of a wind turbine, J. Wind Eng. Ind. Aerodyn., 84, 1-21, https://doi.org/10.1016/S0167-6105(98)00201-3, 2000.

Wharton, S. and Lundquist, J. K.: Atmospheric stability affects wind turbine power collection, Environ. Res. Lett., 7, 1-9, https://doi.org/10.1088/1748-9326/7/1/014005, 2012.

Zahle, F. and Sørensen, N. N.: Characterization of the unsteady flow in the nacelle region of a modern wind turbine, Wind Energy, 13, 271-283, https://doi.org/10.1002/we.418, 2011. 